\title{
SOME BETTER BOUNDS ON THE VARIANCE WITH APPLICATIONS
}

\author{
R. Sharma, M. GUPTA AND G. KAPOOR
}

Abstract. We derive bounds on the variance of a finite universe. Some related inequalities for the roots of the polynomial equations and bounds for the largest and smallest eigenvalues of a square matrix with real spectrum are obtained.

Mathematics subject classification (2010): 60E15, 15A42. equality.

Keywords and phrases: Variance, harmonic mean, eigenvalues, trace, polynomials, the Popoviciu in-

\section{REFERENCES}

[1] T. Popoviciu, Sur les equations algebriques ayant toutes leurs racines reelles, Mathematica, 9, 129$145,(1935)$

[2] J. V. S. NAGY, Uber algebraische Gleichungen mit lauter reellen Wurzeln, Jahresbericht der deutschen mathematiker-Vereingung, 27, 37-43, (1918).

[3] R. Bhatia And C. DAVIs, A better bound on the variance, The American Mathematical Monthly, 107, 353-357, (2000).

[4] R. ShARMA, Some more inequalities for arithmetic mean, harmonic mean and variance, Journal of Mathematical Inequalities, 2, 109-114, (2008).

[5] R. Sharma, A. Kaura, M. Gupta And S. Ram, Some bounds on sample parameters with refinements of Samuelson and Brunk inequalities, Journal of mathematical inequalities, 3, 99-106, (2009).

[6] H. Wolkowicz AND G. P. H. StYAn, Bounds for eigenvalues using traces, Linear Algebra Appl, 29, 471-506, (1980). 